\title{
RESEARCH
}

Open Access

\section{Pathophysiological effects of Tamiflu on liver and kidneys of male rats}

\author{
Wafaa H. Abdel-Ghaffar ${ }^{1}$ and Eman A. Abdelghffar ${ }^{1,2^{*}}$
}

\begin{abstract}
Background: Tamiflu/oseltamivir phosphate (OP), an anti-influenza drug, has a highly doubted safety especially after many cases of abnormal behaviour and deaths reported after being used. Such controversy was also locally and globally generated, especially after being heavily used in COVID-19 treatment protocol. This study was designed to evaluate the effect of three different doses of OP on the liver and kidneys of male adult albino rats through histological approaches, measuring their DNA integrity and biochemical analyses. Different doses of Tamiflu applied to humans were converted to rats, then observed their effects on the liver and kidneys. Rats were divided into four groups. G1: considered as control group. The rest of the three treated groups were received the same calculated dose of Tamiflu (6.75 mg/kg b.w.) in three different durations. G2, G3 and G4 represented the animals orally received OP, in which the rats received OP twice for 5 consecutive days, once for 10 and 45 days, respectively.

Results: Our data showed numerous deleterious necrotic and fibrotic histopathological changes in the liver, and kidneys; as well as necrotic DNA smears, by using electrophoresis, in OP-treated rats of G2 and G4. In addition, OP significantly increased the serum cellular hepatic/renal toxicity markers (ALT, AST, ALP, GGT, indirect bilirubin, urea, creatinine, uric acid, \& $\left.\mathrm{Na}^{+}\right)$. Also, it showed a reduction in the levels of serum total protein, albumin and $\mathrm{K}^{+}$ions in rats of G2 and G4 compared with G1. In G3, OP treatment did not significantly alter hepatic/renal histological, DNA integrity and biochemical analyses in rats.

Conclusions: The therapeutic and long-term prophylactic doses of OP most likely cause structural and functional hepato- and nephrotoxicity in experimentally subjected rats. So, caution must be taken during Tamiflu treatment, and not used for long durations and/or with repetitive doses (time- and/or accumulative-dose-dependent); especially with patients suffer from liver and/or kidney dysfunction, while the short-term prophylactic dose of OP appears to be relatively safe and could be explored for oral medications.
\end{abstract}

Keywords: Histopathology, Biochemical analyses, DNA electrophoresis, Oseltamivir phosphate, Rats

\footnotetext{
*Correspondence: eman_a@sci.asu.edu.eg

${ }^{1}$ Department of Zoology, Faculty of Science, Ain Shams University, Cairo,

Egypt

Full list of author information is available at the end of the article
} 


\section{Graphical Abstract}

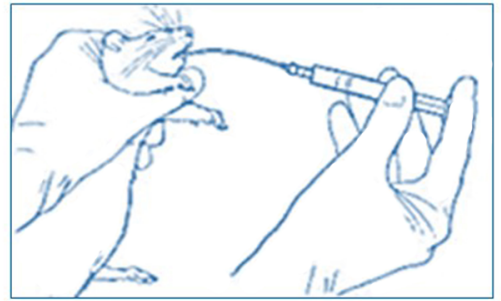

Oral administration of male albino rats

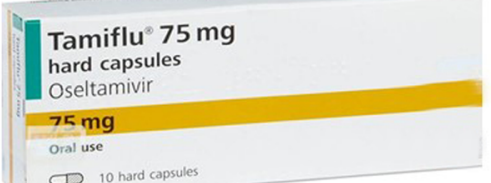

G2: $6.75 \mathrm{mg} / \mathrm{kg}$ b.w./twice daily $/$ p.o./5 days (parallel to the therapeutic dose applied to humans)

G3: $6.75 \mathrm{mg} / \mathrm{kg}$ b.w./once daily/p.o./10 days (parallel to the short-term prophylactic dose applied to humans).

G4: $6.75 \mathrm{mg} / \mathrm{kg}$ b.w./once daily/p.o./45 days (parallel to the long-term prophylactic dose applied to humans).
Serum biochemical alteration (G2\&4):

A. Elevation in the serum hepatic toxicity markers:

ALT, ALP, ALP, GGT, direct bilirubin.

Total protein, Albumin

B. Elevation in the serum renal toxicity markers:

Urea, creatinine, uric acid, $\mathrm{Na}^{+}$ions.

$\checkmark \mathrm{K}^{+}$ions.

Hepatic histopathological alteration (G2\&4):

- Hepatocellular necrosis \& degenerative changes.

- Extensive vacuolization in hepatocytes.

- Centrilobularnecrosis.

- Congested \& dilated central veins \& blood sinusoids.

- Infiltration of mononuclear cells in hepatic lobules.

Renal histopathological alteration (G2\&4):

- Atrophic glomeruli, glomerular capsules \& tubular dilatation.

- Severe tubular leakage.

- Necrosis in glomeruli, convoluted tubules, Bowman capsules.

- Infiltration by inflammatory cells.

- Mild tubular haemorrhage.

- Disintegration of tubularepithelia

Hepatic \& renal DNA degradation due to necrosis (G2\&4).

\section{Background}

Recently, Tamiflu (oseltamivir phosphate, OP)—working as neuraminidase inhibitor-received high attention because of COVID-19 pandemic. In 1998, Mendel et al. [1] stated that Tamiflu is designed to be highly specific to the influenza virus. Due to this high specificity, it was suggested that Tamiflu would be effective in the treatment of the coronavirus. But, unfortunately it is worth to mention that the laboratory testing-conducted by Hong Kong University-demonstrated that OP did not have any antiviral effect on the novel coronavirus [2]. Also, the effectiveness of Tamiflu is doubted among researchers, due to publication bias policy (publishing favourable studies and not publishing unfavourable studies) adapted by its original manufacturer-Roche-that refused to release its own trial data [3]. So, it would not be possible to know the actual side effects until all Roche's data are being honestly published [4-6]. Tamiflu is indicated as prophylactic influenza drug and as therapeutic for uncomplicated acute illness due to influenza in patients 1-year-old and the older ones who have been symptomatic for no more than 2 days [7]. However, the efficacy and efficiency of Tamiflu treatment (reduction of the viral serious complications and hospitalization) is still subject of debate. Several authors studied the safety, and tolerability of $\mathrm{OP}-$ since the early beginning of drug launching $-[8,9]$, and recommended its usage. Conversely, others reported that Tamiflu administration cause several adverse effects on many vital organs [10-14].

In fact, from another critical point of view, Tamiflu was tested in 1998 and released as a drug in 2001. According to FDA, the newly developed drug requires several tests designed (in vitro/in vivo) to determine its major toxicities prior to be first used by man [15]. FDA (1991) [16] published that the drugs examination protocols and the procedures take an average of 10 years for an experimental drug to travel from the laboratory to the public pharmacies in USA - which is inconsistent with what was happened with Tamiflu (FDA four main phases: the average period per each phase differ, and ranged from 1-3.5 years). The latter statements oppose the fact that Tamiflu is being licensed after two years only! Although Tamiflu is already manufactured in USA, these rules did not apply to it!

So, conflicts between supports and opponents emerged (because of Tamiflu pathological alterations') to use Tamiflu as a therapeutic and prophylactic drug that is coincided with the lack of fixed; unified, complete, clear or even justified data bases. Collectively, from all of the aforementioned reasons, this designed study became a must. This study designed to evaluate the effect of three different doses of Tamiflu itself as a drug on the main vital organs represented by the liver and kidneys. The resulted drug 
alterations will be assessed histopathologically, biochemically, in addition to DNA electrophoretic analyses. to rats according to the equation "Table" given by Paget and Barnes [20], as follows:

Animal dose $(\mathrm{mg} / 200 \mathrm{~g})=$ Dose of the humanweighing $70 \mathrm{~kg} \times$ conversion factor

Animal dose $(\mathrm{mg} / 200 \mathrm{~g})=75 \times 0.018=1.35 \mathrm{mg} / 200 \mathrm{~g}$

Animal dose $(\mathrm{mg} / \mathrm{kg})=1.35 \times 5=6.75 \mathrm{mg} / \mathrm{kg}$

\section{Methods}

\subsection{Chemicals and drug}

TAMIFLU ${ }^{\circledR} /$ oseltamivir phosphate $(75 \mathrm{mg})$ is manufactured by F. Hoffman-La Roche, Gilead Sciences, Foster City, California, USA. It is available in the market as capsules for oral administration. ALT (Alanine aminotransferase), AST (aspartate aminotransferase), alkaline phosphatase (ALP), gamma-glutamyltransferase (GGT), total and direct bilirubin, total protein, albumin, urea, creatinine, uric acid, sodium $\left(\mathrm{Na}^{+}\right)$and potassium $\left(\mathrm{K}^{+}\right)$were colorimetrically determined by using Bio-diagnostic Kits (Giza, Egypt). All of the other used chemicals, solvents and reagents were of analytical and pure grade. Also, indirect bilirubin was calculated as total bilirubin value minus direct bilirubin value.

\subsection{Animals}

Forty male adult Wistar albino rats (Rattus norvegicus), ranging between 3 and 4 months and weighing 150-200 g, were obtained from the Institution of Animal Veterinary and Serum Vaccine Research, Abbassia (Cairo, Egypt). The rats have been housed in suitable-sized cages in the animal house of Zoology Department, Faculty of Science, Ain Shams University, for 2 weeks as an accommodation period for them. Water and standard pellets of animal diet were supplied ad libitum.

\subsection{Experimental design and treatment schedule calculation:}

The rats were randomly divided into 4 groups $(n=10)$ as follows: Group 1 (G1): The control animals, which received (orally/daily) distilled water. All of the treated groups (G2G4) were orally administrated by $6.75 \mathrm{mg} / \mathrm{kg}$ daily, but differ in the duration as follows: Group 2 (G2): The animals received Tamiflu twice, for 5 consecutive days according to Lee et al. [17]. This treatment is parallel to the therapeutic dose applied to humans $(75 \mathrm{mg} / 70 \mathrm{~kg}$ b. w. of Tamiflu twice orally/daily for 5 consecutive days). Group 3 (G3): The rats received Tamiflu once for 10 days according to Hayden et al. [18]. This treatment is parallel to the short-term prophylactic dose applied to humans $(75 \mathrm{mg} / 70 \mathrm{~kg}$ b. w. of Tamiflu orally/ daily for 10 consecutive days). Group 4 (G4): The animals received Tamiflu once for 45 days according to Peter et al. [19]. This treatment is parallel to the long-term prophylactic dose applied to humans. The above dosages were converted
To prepare a solution of $75 \mathrm{mg}$ of the drug, the powder inside the gelatinous capsule ( $75 \mathrm{mg}$ of Tamiflu) was dissolved in $75 \mathrm{ml}$ distilled water. So, each $1 \mathrm{mg}$ of the drug will be dissolved in $1 \mathrm{ml}$ of the prepared solution. The prepared drug was administrated orally by stomach tube that contained the calculated dose applied orally to rats in different durations according to the group.

\subsection{Blood collection and biochemical investigations}

The blood samples were immediately collected in plain test tubes after scarifying the anaesthetized rats, and left to clot, then centrifuged (5000 rpm, $15 \mathrm{~min}$ ). The sera were kept at $-80{ }^{\circ} \mathrm{C}$ for further biochemical analyses (ALT, AST, ALP, GGT, bilirubin profiles, protein, albumin, urea, creatinine, uric acid, electrolytes as $\mathrm{Na}^{+}$and $\left.\mathrm{K}^{+}\right)$.

\subsection{Tissues sampling and histological investigations}

The dissected liver and the kidneys were cut into small pieces $(\approx 0.5 \mathrm{~cm})$. The pieces were washed in saline, fixed in liquid Bouin's solution, then processed and stained in H\&E for histopathology. Sections were photographed using a digital microscope camera (Hirocam, MA88-500 Eyepiece) attached to a Magnus microscope (MLX-B Plus SP, China). For each renal section, 3 random non-overlapping high power areas were graded semi-quantitatively for lesion severity according to the following scoring system: 0 , no lesion; 1 , mild damage; 2 , moderate damage; 3 , severe damage.

\subsection{Molecular investigations: DNA fragmentation}

For DNA extraction and fragmentation assay (apoptosis or necrosis detection), the used method based on salting out extraction (refer to Aljanabi and Martinez [21], and modified by HassabEl-Nabi [22]). In this method, $10 \mathrm{mg}$ liver or kidneys' tissues was squeezed in micro tubes and lysed by using $600 \mu \mathrm{l}$ lysing solution $\left(50 \mathrm{mM} \mathrm{NaCl}, 10 \mathrm{mM}\right.$ Tris, $10 \mathrm{mM} \mathrm{Na}{ }_{2}$ EDTA, $0.5 \%$ SDS, pH 8.3), and then shaken gently. Finally, after several technical steps, the resulted mixture of each tube was directly loaded on agarose gel. The gels were 
photographed using a digital camera; the DNA was visualized as necrotic smears which were measured using Gel-Pro program.

\subsection{Statistics}

Data were presented as mean \pm SE. Statistical analysis was performed with one-way ANOVA for biochemical and electrophoretic analyses of this study using Graph Pad Prism software (version 5.3 Bic Executable, Graph Pad Software Inc.). The optical density of the DNA necrotic damage was detected by using Image $G$ program. $P$ value of $<0.05$ was considered significant.

\section{Results}

\subsection{Histological findings}

\subsubsection{The liver}

The microscopical examination of the control liver sections (Fig. 1) reveals normal structure of hepatocytes. The examination of the liver sections of Tamiflu-treated groups (G2 to G4) showed variable histopathological alterations. In G2: the examination of this group revealed from mild to moderate alterations. Mostly, the blood sinusoids together with the central veins were congested (Fig. 2A). Also, the hepatocytes were either swollen and showed basophilic-stainability or shrunken and vanished (Fig. 2A, B). In addition, most branches of the hepatic portal veins were dilated with a deformed and ruptured endothelial lining as shown in Fig. 2C. The hepatocytes' were either necrotic, pyknotis, pleomorphic or even vanished. The cytoplasm of the hepatocytes showed coagulation and vacuolation. Numerous inflammatory cells as

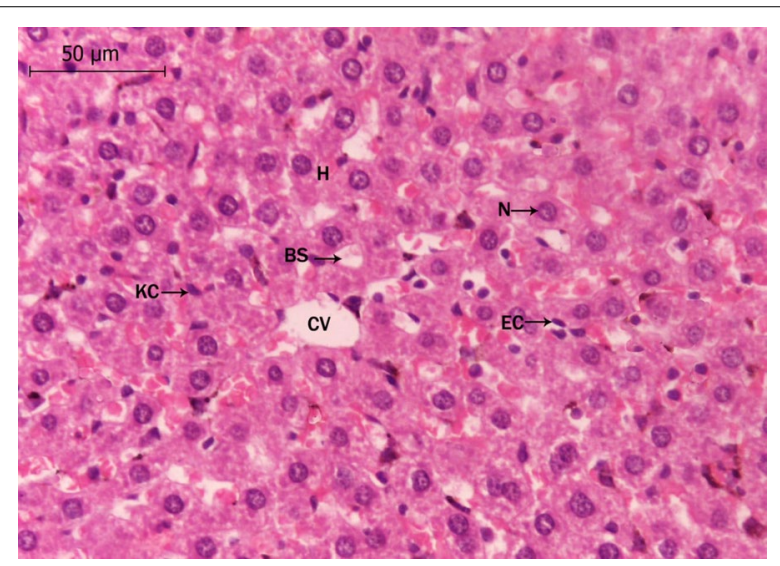

Fig. 1 A photomicrograph of a control liver section of a rat showing the typical structure of the liver cells $(H)$, forming a network around the central vein (CV). Notice that the liver cells' nuclei (N) are large, spherical and almost centrally located. Notice Küpffer cells (KC) in association with the blood sinusoids (BS), and endothelial cells (EC, $X$ $400, \mathrm{H} \& \mathrm{E}$
Langhans giant cells invaded the deteriorated areas of the liver sections; it presumably scavenges the degenerated cells (as shown in Fig. 2D). In G3: almost normal hepatocytes were shown except few affected spots (Fig. 3A, B). These spots exhibited degenerated hepatocytes with darkly stained cytoplasm located nearby the eroded endothelium of the affected central veins (Fig. 3A). Most hepatocytes exhibited foamy cytoplasm (Fig. 3A, B). Non-homogeneous and sever picture of alterations was observed in group 4. The examination of the liver sections of G4 showed focal coagulative necrosis (Fig. 4A, B) of hepatocytes that surrounded the central vein. This is accompanied with heavy accumulation of mononucleated cells that invaded the destructed area. The nuclei showed abnormal chromatin distribution. By dosage accumulation and long period of oral administration, the hepatocytes showed areas of vacuolar and vanished cytoplasm (Fig. 4C, D).

\subsubsection{The kidneys}

The microscopical examination of the control rats' kidneys shows typical normal structure of the cortex and medulla (Fig. 5A, B \& Fig. 6A and Table 1). The histological sections of the kidneys of Tamiflu-treated groups (G2, G3 and G4) are presented by Figs. 5C-F \& 6B.

The alterations were pronounced with variable degree of severity as shown in G2 and G4. Such alterations became more sever in G2 and G4, while in G3, such alterations were restricted to limited spots in the examined sections of this group. The kidney sections showed marked necrosis of the tubules. In the cortices, the glomeruli displayed large mesangial spaces and disturbed capillary architecture. The glomeruli were either clefted, shrunken or degenerated. The epithelium of the proximal and distal tubules displayed variable degrees of stainability. Some of these epithelial cells appeared faintly stained, while other cells showed homogeneous dark stain with pyknosis and/karyolysis. Mainly, most of the necrotic cells fell into the tubular lumen obliterated them. In various sections, the intertubular spaces were widened and this was accompanied with inflammatory infiltrate. The interstitial areas among the renal tubules together with the lumina of the renal tubules were congested with blood cells, which were highly obvious in Fig. 5E-G. The aforementioned figures exhibited widened, thickened and damaged renal blood vessels.

In the medullary region, the examined sections of G4 showed marked necrotic degeneration of the epithelial renal tubules accompanied with mononuclear cells infiltration, as shown in Fig. 6B, compared to that of the control section (Fig. 6A). Also, this was accompanied with several spots of tubular congestion and haemorrhage 

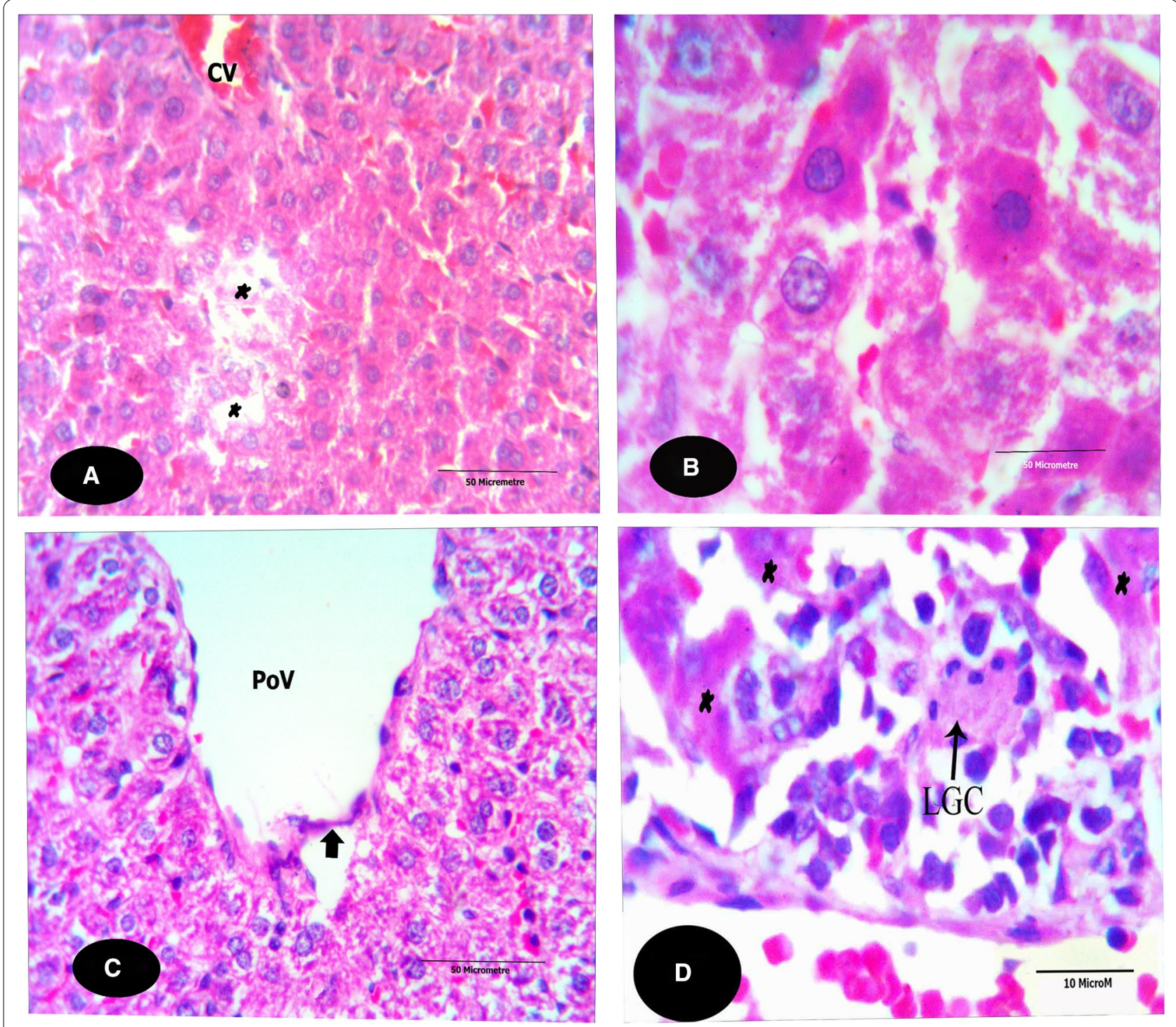

Fig. 2 A-D Photomicrographs of liver sections of G2 stained with H\&E. A shows areas of faintly stained autolysed hepatocytes (*). The blood sinusoids and the CV are congested with blood. (X100). B displays swollen and basophilic-stained hepatocytes. The hepatocytes exhibit pleomorphic nuclei. The nuclei are either pyknotic or vanished. (X1000). C shows a dilated branch of the portal vein (PoV) which exhibits a deformed and ruptured endothelial lining. The tissue architecture is disrupted. Notice the autolysed narrow area of the tissue underneath the endothelial lining of the vein. The cytoplasm of the hepatocytes is coagulated and vacuolated. Also, the hepatocytes'nuclei are shrunken. (X100). D shows an enlarged area nearby a CV (at the bottom of the figure). The hepatocytes show coagulative necrosis (*). Also, a Langhans giant cell (LGC) invades the area; it presumably scavenges the degenerated cells. (X1000)

(such alteration was markedly pronounced and restricted to this group. The degree of histopathological alterations indices in the kidneys of each group due to OP administration were semi-quantitatively analysed, summarized and represented in Table 1 compared to the control group.

\subsection{Biochemical findings}

The serum markers of hepatic/renal toxicities (ALT, ALP, GGT, direct bilirubin, urea, creatinine, uric acid, $\mathrm{Na}^{+}$ levels) were significantly increased $(P<0.05-0.001)$ in rats of G2 (treated with Tamiflu twice daily for 5 days) and in rats of G4 (treated with Tamiflu once daily for 45 days) compared to the control group (G1); as shown in Table 2. On the other hand, no significant changes recorded $(P>0.05)$ in total, and direct bilirubin levels in the rats of either G2 or G4 compared to G1. Moreover, levels of serum total protein, albumin and $\mathrm{K}^{+}$were significantly decreased $(P<0.05-0.001)$ in the rats of either G2 or G4 compared to G1. On the contrary, all of 


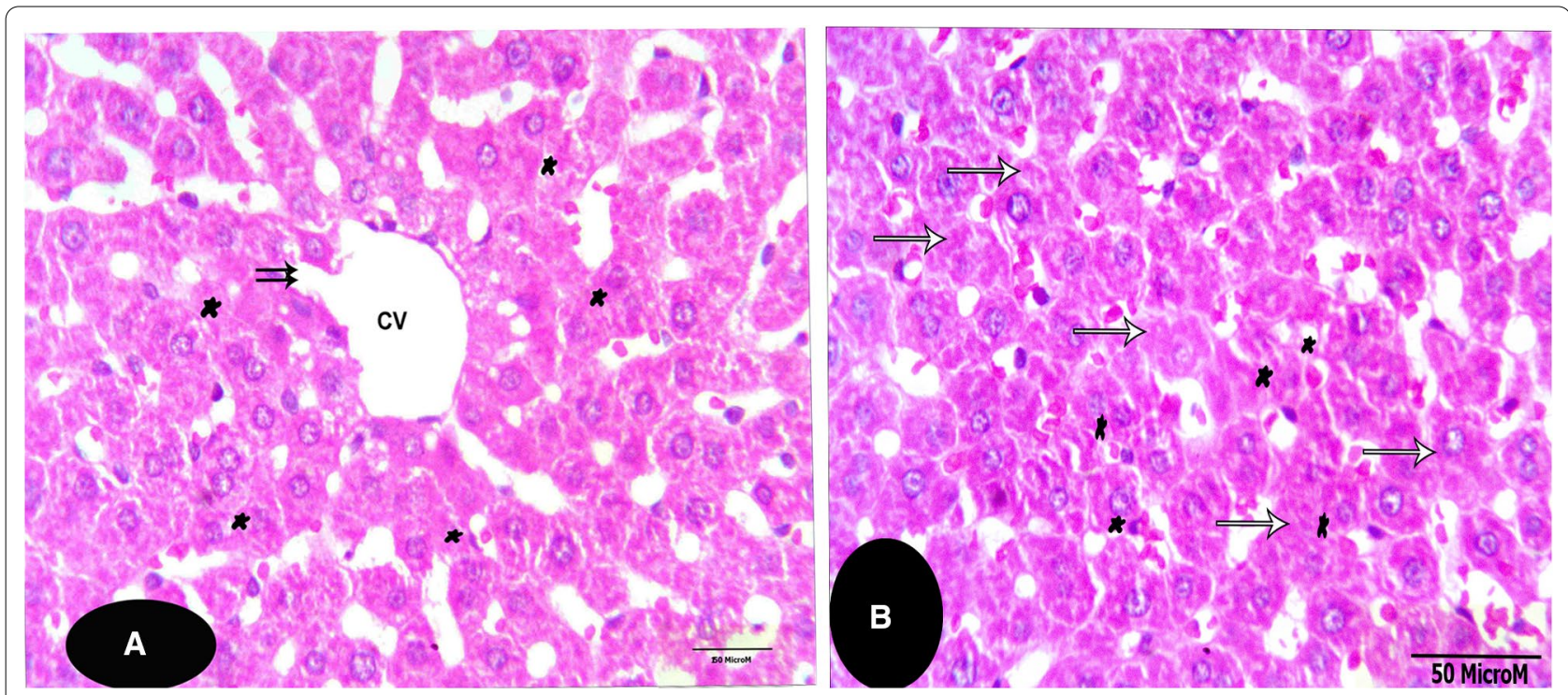

Fig. 3 A, B Photomicrographs of liver sections of G3 (X 400, H\&E). A displays a central vein (CV) with a partially eroded wall (arrows). Some hepatocytes display foamy cytoplasm $\left({ }^{*}\right)$, while the rest of hepatocytes are shrunken, and exhibit darkly stained cytoplasm. B shows hepatocytes with foamy cytoplasm $(*)$. The hepatocytes exhibit degenerated and karyolysed nuclei (arrows). The nuclei of other hepatocytes display abnormal chromatin distribution

the following parameters assessed in this study did not change significantly $(P>0.05)$ in rats of G3 treated with Tamiflu once daily for 10 days except serum albumin was significantly decreased $(P<0.05)$ in rats of G3 compared with the G1.

\subsection{DNA electrophoretic findings}

The severity of hepatic DNA fragmentation was remarkably increased $(\mathrm{P}<0.001)$ in $\mathrm{G} 2$ at 600,400 and $200 \mathrm{bp}$ that match the mean values $138.90 \pm 7.14,141.70 \pm 5.04$ and $138.70 \pm 3.87$, respectively; as well as in G4, their mean values equal $154.80 \pm 3.36,181.2 \pm 3.12$ and $162.90 \pm 4.10$, respectively; compared with that of the control group represented by $76.40 \pm 5.18,46.21 \pm 5.13$ and $27.15 \pm 2.92$, respectively; as shown in Fig. 7A (lanes $4,5 \& 6)$ and Table 3 . In addition, a very highly significant increase of the hepatic DNA optical density $(P<0.001)$ was obtained in the mean values at 600 and $400 \mathrm{bp}$ equal $117.70 \pm 8.40$ and $102.20 \pm 3.62$, respectively, in G3 compared with the obtained mean values of the control group that equal $76.40 \pm 5.10$ and $46.21 \pm 5.13$, respectively, as shown in Figs. 7A (lanes 7, 8 \& 9) and Table 3. On the other hand, the mean value of the hepatic DNA optical density at $200 \mathrm{bp}$ location of G3 $(29.34 \pm 2.12)$ did not show any change $(P>0.05)$ compared to the control group $(27.15 \pm 2.92)$.

In Fig. 7B and Table 3, significant increase $(P<0.01$, and $P<0.001)$ were shown in the mean values of the kidneys' DNA optical densities at 200 and $600 \mathrm{bp}$ locations of G2 equal $58.00 \pm 4.80$ and $122.30 \pm 7.01$, respectively; also, a significant increase $(P<0.001)$ were observed in the mean values of the kidneys' DNA optical densities at 200, 400 and $600 \mathrm{bp}$ locations of G4 which recorded as: $\quad 154.80 \pm 3.36,124.10 \pm 7.76$ and $142.00 \pm 4.04$, respectively; compared with that of the control group: $23.67 \pm 5.69,25.83 \pm 7.93$ and $34.66 \pm 5.68$, respectively. On the other hand, the mean values of the kidneys' DNA optical densities at 200,400, 600 bp location of G3 did not show any remarkable alterations $(P>0.05)$ compared to the control group.

\section{Discussion}

It is worth to mention that till now there are no data on the safety, tolerability, or even effectiveness of the influenza vaccines in the patients with mild COVID-19 or even with those who have recovered from COVID-19. Therefore, the safety and efficacy of vaccinating persons have not been documented yet [23]. So, this study was carried out to investigate the probable effect of Tamiflu which listed as the main drug in the treatment protocol.

Our biochemical findings showed significant increases in the serum toxicity markers of both liver and kidneys (ALT, AST, ALP, GGT, indirect bilirubin, urea, creatinine, uric acid and $\mathrm{Na}^{+}$), which were accompanied by decreases in the levels of serum total protein, albumin and $\mathrm{K}^{+}$ions of G2 (The therapeutic dose) and G4 (long-term prophylactic dose). On the other hand, neither the liver's nor kidneys' serum functions 

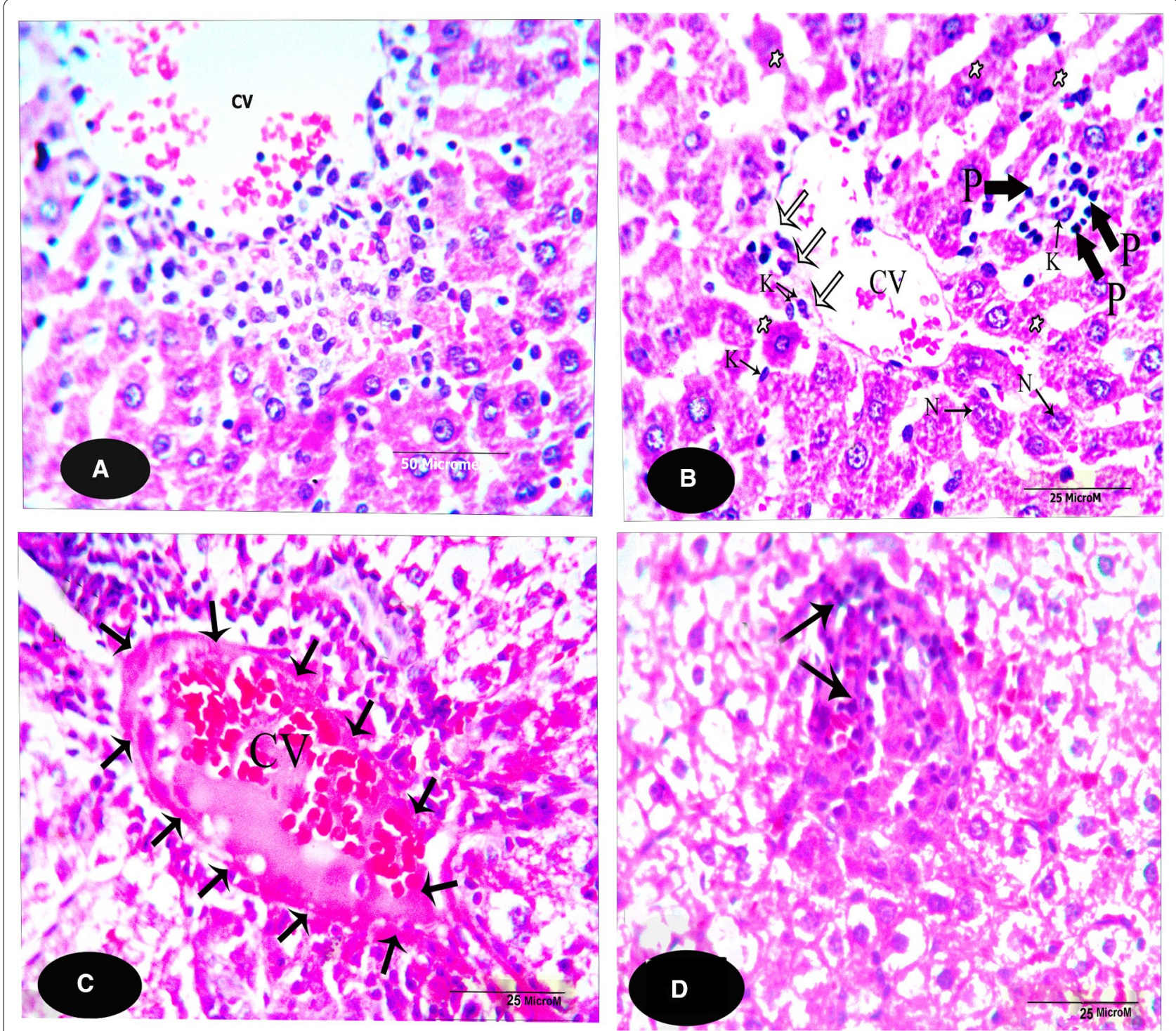

Fig. 4 A-D Photomicrographs of a liver sections of G4 (X 400, H\&E). A focuses on the eroded CV which is accompanied with heavy accumulation of mononucleated cells. Generally, the hepatocytes' nuclei in such necrotic area exhibit abnormal chromatin distribution. B shows a CV that displays eroded endothelium lining (white arrows). The mononuclear cells invade the eroded area around the central vein. Generally, most of the hepatocytes are shrunken, degenerated and darkly stained; this is accompanied with widening of the BS. Notice that the hepatocytes'nuclei are pleomorphic. C shows a dilated CV that displays a marked thickening of its endothelial lining cells (arrows). The central vein's lumen is largely occluded with a mass of blood clot which, apart from a few remains of red blood cells, is homogeneous, hyaline and acidophilic. D shows a necrotic area of hepatocytes (arrows). Most of the hepatocytes are highly evacuated (vanished cytoplasm)

were affected by Tamiflu in G3 (short-term prophylactic dose); except the serum albumin level which was significantly decreased compared with the control group. Al-Rikabi [10] and [11] reported significant increases of hepatic and renal serum markers in the rats that treated with Tamiflu (1 $\mathrm{mg} / \mathrm{kg} / 6$ weeks), with significant increase in serum ALP, direct bilirubin and uric acid, and significant decrease in ALT activity and indirect bilirubin. Also, the results by El-Sayed and Al-Kahtani
[24] showed significant elevations in AST and ALT activities in male and female rats that dosed with Tamiflu $(2.2 \mathrm{mg} / \mathrm{kg} / 5$ days); the same dose caused oxidative stress and acute toxicity in both genders. Akanji et al. [25] reported that the increase in the serum enzymes as ALT, AST, ALP, GGT might be due to permeability alterations in the plasma membrane leading to enzyme leakage from liver tissues into the blood stream, leads 

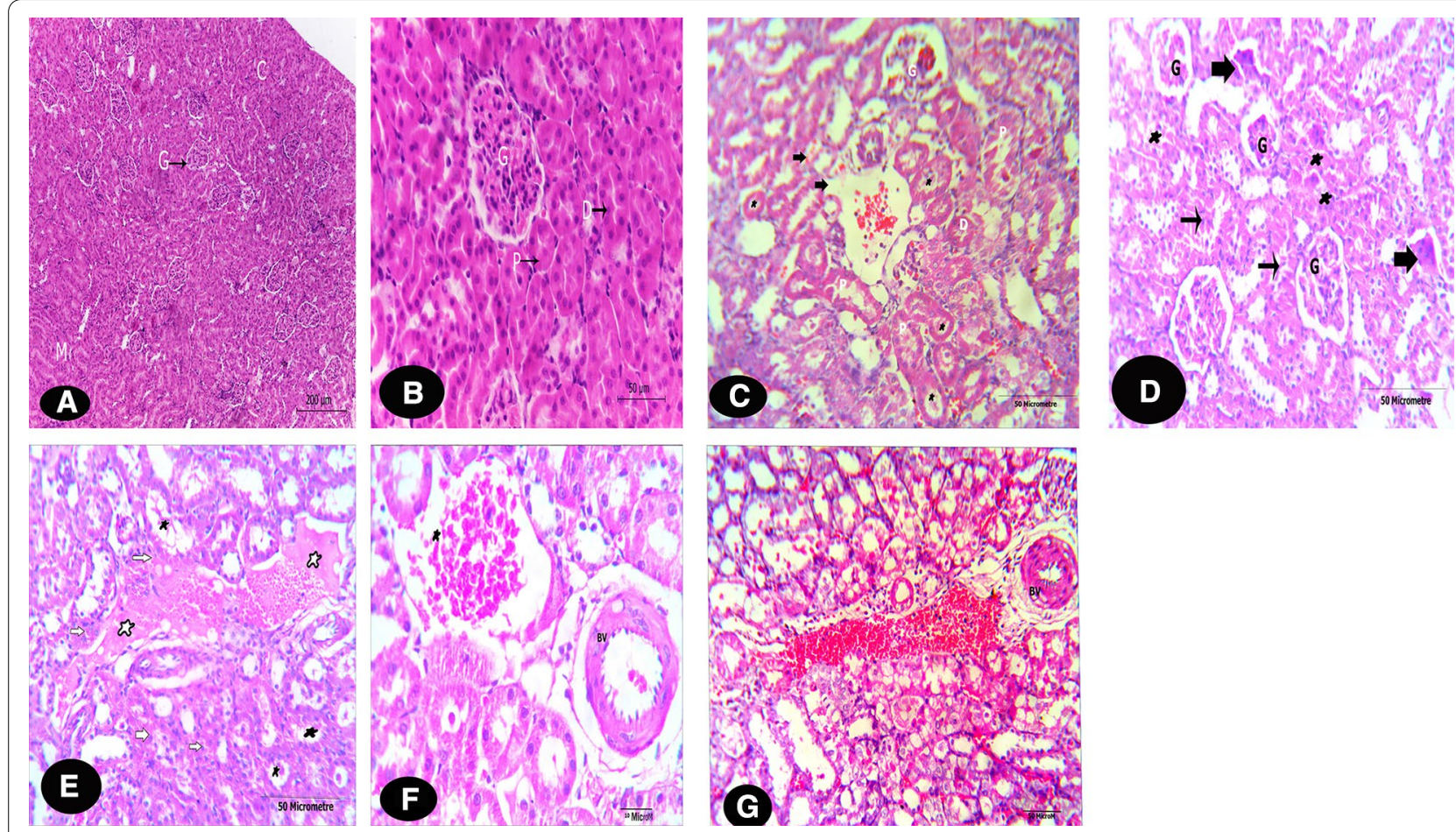

Fig. 5 A-G Photomicrographs of T. S. of kidneys of rats of G1 showing part of the cortices (C, H\&E). A The cortex is characterized by the presence of numerous glomeruli (G). (X 100, H\&E). B A magnified part of the cortex of $\mathbf{A}$ exhibit normal typical structure of G, proximal convoluted tubules (P) and distal convoluted tubules (D). (X 400, H\&E). C A photomicrograph of T. S. of kidney of G2 showing proximal (P) \& distal (D) tubular necrosis with variable degrees of stainability. The necrotic cells fell into the tubules' lumen and obliterated them $(*)$. Notice the vacuolar changes (arrows), the $\mathrm{G}$ degeneration and capsular thickening. (X 100, G2, H\&E). D A photomicrograph of T. S. of kidney of G3 showing moderate alterations restricted to few spots per each examined section, and hypercellularity (*). The glomerular alterations include clefted and shrunken glomeruli ( $G$ and arrow, respectively). (X 100, G3, H\&E). E A photomicrographs of T. S. of kidneys of G4 showing sever degradation of the kidney tubules (white-arrows). In most cases, the tubules show obliterated lumina (black asterisk), and hypercellularity in between. The interstitial areas among the renal tubules together with the lumina of the renal tubules were congested with blood cells (white asterisk). Notice the cellular infiltration (thin black arrow). (X

$100, \mathbf{G 4})$. F \& G showing degenerated, widened, and thickened BVs, plus severe vacuolar degeneration. Notice variable degrees of necrotic changes in both sections. The interstitial areas among the renal tubules together with the lumina of the renal tubules were congested with blood cells. (X 400 and 100; respectively, G4)

to hepatocellular functions impairment (such as pyknosis/necrosis).

Significant increases in the liver enzymes markers in G2 and G4 imply a loss of cellular membrane integrity. Aminotransferases catalyse the interconversion of AAs and oxoacids by transferring amino groups in protein metabolism and gluconeogenesis. ALP is a potent anti-inflammatory mediator, protects tissues from damage/injury. Also, it plays an integral role in metabolism and biosynthesis of energy macromolecules within the liver, and breaks down proteins and catalyses the removing of phosphoric esters. AST, ALT and GGT are the most important indicators of hepatocellular injury/necrosis, inflammation and metabolic disorders [26].

The main cause of hyperbilirubinemia could be due to rise an indirect serum bilirubin (unconjugated bilirubin), which may result from poor conjugation, or decreased liver uptake of an indirect bilirubin or/ and rapid synthesis (haemolysis) in drug induced liver injury [27]. Moreover, elevation of serum indirect bilirubin in G2 and G4 may be due to free fatty acids which displace indirect bilirubin from its attachment to plasma albumin [28]. Hypoproteinemia can also be caused by liver impairment, which reduces the synthesis of plasma proteins like albumin (hypoalbuminemia) [27]. Other previous studies indicated that the protein depletion referred to impairment in the secretory function of the liver arising probably from hepatocellular injury [29], or increased catabolism [30]. Hyperlipidemia is a well-known risk factor for fatty liver infiltration, which can lead to liver failure. Hypercholesterolemia has been linked to an increase in the production of oxygen free radicals, which has been linked to negative effects on organ tissues such as blood vessels, liver and kidney [27]. All of the aforementioned 

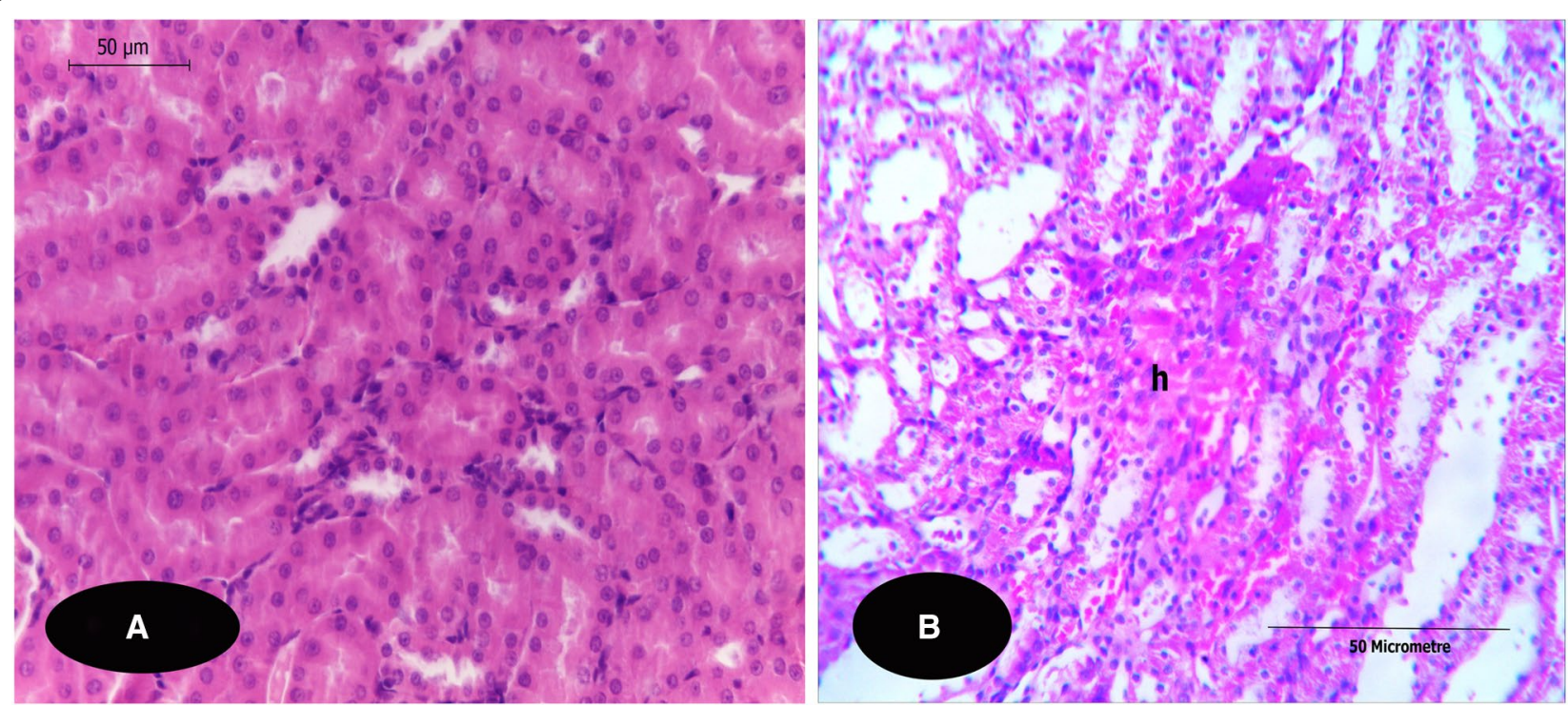

Fig. 6 A, B T. S. of kidneys of rats show parts of the medullae stained with H\&E. A T. S. of a kidney of G1 (control rat) showing a typical structures of the medullary tubules. (X 400). B T. S. of a kidney of $\mathbf{G} 4$ showing blood congestion/haemorrhage (h) which is detected on the medullary region in of this group (X 100). Notice: both $\mathbf{G} \mathbf{2} \mathbf{3} \mathbf{3}$ did not show any histopathological alterations in the medullary regions of the examined kidney sections compared to $\mathbf{G} \mathbf{1}$ sections

Table 1 The effect of Tamiflu on renal histology of various treated groups compared to that of the control group

\begin{tabular}{|c|c|c|c|c|}
\hline & G1 & G2 & G3 & G4 \\
\hline \multicolumn{5}{|l|}{ Cortices alterations } \\
\hline Glomerulus changes & $0.00 \pm 0.00$ & $1.38 \pm 0.23^{* * *}$ & $0.33 \pm 0.80$ & $2.48 \pm 0.20^{* * *}$ \\
\hline Capsular thickening & $0.00 \pm 0.00$ & $0.91 \pm 0.26^{* *}$ & $0.19 \pm 0.03$ & $1.12 \pm 0.18^{* * *}$ \\
\hline Proximal con. tubule necrosis & $0.00 \pm 0.00$ & $1.80 \pm 0.07^{* * *}$ & $0.36 \pm 0.10$ & $2.65 \pm 0.14^{* * *}$ \\
\hline Epithelial vacuolation & $0.00 \pm 0.00$ & $1.39 \pm 0.35^{* * *}$ & $0.64 \pm 0.4^{* * *}$ & $2.80 \pm 25^{* * *}$ \\
\hline hypercellularity & $0.00 \pm 0.00$ & $1.09^{*} \pm 0.41^{*}$ & $0.20 \pm 0.07$ & $2.18 \pm 0.30^{* * *}$ \\
\hline \multicolumn{5}{|l|}{ Medullae alteration } \\
\hline Haemorrhage/(extravasated RBCs) & $0.00 \pm 0.00$ & $0.09 \pm 0.10$ & $0.20 \pm 0.28$ & $1.93 \pm 0.39^{* * *}$ \\
\hline
\end{tabular}

Data: mean \pm SE., $0=$ no lesion; $1=$ mild effects; 2 = moderate effects; $3=$ severe lesions. G1: control, G2: therapeutic design, G3: short-term prophylactic design, G4: long-term prophylactic design. $P$ values: No asterisks $=$ non-significant $(P>0.05)$, * Significant $(P<0.05),{ }^{* * H i g h l y ~ s i g n i f i c a n t ~}(P<0.01),{ }^{* * *}$ Very highly significant $(P<0.001)$ compared to their control, using one-way ANOVA

alterations represent either an increase or a decrease in a certain parameter(s) investigated in this study.

Xenobiotics caused oxidative stress, which is shown histologically. The results of the present study showed foamy/cytoplasmic vacuolization. The latter alteration was explained by Santucci et al. [31] due to accumulations of the neutral lipids. The latter cause the foamy appearance of the cells, originate at the ER, accumulate in it and pinched off the ER membrane into the cytosol. Abdel-Ghaffar [13] mentioned that the accumulation of the lipid droplets was a prominent alteration observed ultrastructurally in transverse sections of the testes of Tamiflu-administrated rats.
Also, mononucleated cells infiltration (Küpffer cells/ LGC/histiocytes) and haemorrhage (dilatation of PoV/ congested BS) were seen in the present study which indicate chronic inflammation. The previous observations agreed with those observed by Michael and Cynthia [32]. The authors explained that mononucleated and Küpffer cells activation and others promoting due to tissue damage. While Farrag et al. [33] explained that the drug caused the changes should be listed among "drugsinduced liver injury". The latter type of drugs defined as "drug-induced critical alterations of hepatocytes that trigger the immune systems of susceptible hosts to infiltrate their livers and assault/damage hepatocytes, which 
Table 2 The influence of Tamiflu on the serum markers of hepatic/renal toxicities of the various treated groups compared to that of the control group

\begin{tabular}{|c|c|c|c|c|c|c|}
\hline \multirow[t]{2}{*}{ Parameters } & & & \multicolumn{4}{|l|}{ Groups } \\
\hline & & & G1 & G2 & G3 & G4 \\
\hline ALT & & (IU/L) activity & $93.33 \pm 9.94$ & $136.70 \pm 9064^{* *}$ & $118.00 \pm 5.57$ & $161.50 \pm 4.46^{* * *}$ \\
\hline AST & & & $184.80 \pm 23.05$ & $281.00 \pm 19.77^{*}$ & $251.50 \pm 21.14$ & $301.00 \pm 13.47^{* *}$ \\
\hline ALP & & & $51.19 \pm 4.36$ & $69.50 \pm 2.39^{* *}$ & $61.42 \pm 2.05$ & $91.92 \pm 2.77^{* * *}$ \\
\hline GGT & & & $3.83 \pm 0.30$ & $4.33 \pm 0.33^{* *}$ & $2.83 \pm 0.30$ & $5.50 \pm 0.22^{* * *}$ \\
\hline Total & Bili & $(\mathrm{mg} / \mathrm{dl})$ & $0.57 \pm 0.04$ & $0.62 \pm 0.07$ & $0.55 \pm 0.05$ & $0.70 \pm 0.03$ \\
\hline Direct & & & $0.27 \pm 0.02$ & $0.15 \pm 0.03$ & $0.18 \pm 0.04$ & $0.15 \pm 0.04$ \\
\hline Indirect & & & $0.30 \pm 0.06$ & $0.40 \pm 0.05^{*}$ & $0.37 \pm 0.05$ & $0.55 \pm 0.02^{* *}$ \\
\hline Urea & & & $15.67 \pm 0.80$ & $19.74 \pm 0.89^{*}$ & $17.83 \pm 0.54$ & $36.85 \pm 1.50^{* * *}$ \\
\hline Creatinine & & & $0.60 \pm 0.02$ & $0.68 \pm 0.02^{*}$ & $0.64 \pm 0.02$ & $0.72 \pm 0.02^{* *}$ \\
\hline Uric acid & & & $1.98 \pm 0.02$ & $2.19 \pm 0.04^{* *}$ & $2.05 \pm 0.04$ & $2.92 \pm 0.03^{* * *}$ \\
\hline Total protein & & $(g / d l)$ & $6.42 \pm 0.17$ & $5.47 \pm 0.32^{*}$ & $5.70 \pm 0.16$ & $5.05 \pm 0.23^{* *}$ \\
\hline Albumin & & & $3.36 \pm 0.13$ & $2.37 \pm 0.20^{*}$ & $2.57 \pm 0.20^{*}$ & $2.26 \pm 0.19^{* *}$ \\
\hline $\mathrm{Na}^{+}$ & & $(\mathrm{mmol} / \mathrm{L})$ & $120.60 \pm 0.87$ & $126.70 \pm 1.69^{*}$ & $122.50 \pm 0.97$ & $136.20 \pm 1.82^{* * *}$ \\
\hline $\mathrm{K}^{+}$ & & & $4.73 \pm 0.24$ & $3.79 \pm 0.09^{*}$ & $4.38 \pm 0.25$ & $3.25 \pm 0.14^{* * *}$ \\
\hline
\end{tabular}

Values: mean \pm SE. ALT = Alanine aminotransferase, AST = Aspartate aminotransferase, ALP = Alkaline phosphatase, GGT $(\gamma-G T)=$ Gamma-glutamyltransferase, Total $\mathrm{Bili}=$ total bilirubin, Direct Bili. = direct bilirubin, Ind. Bili. = indirect bilirubin. G1: control, G2: therapeutic design, G3: short-term prophylactic design, G4: long-term prophylactic design. $P$ values: No asterisks $=$ non-significant $(P>0.05),{ }^{*}$ Significant $(P<0.05),{ }^{* *}$ Highly significant $(P<0.01), * * *$ Very highly significant $(P<0.001)$ compared to their control, using one-way ANOVA
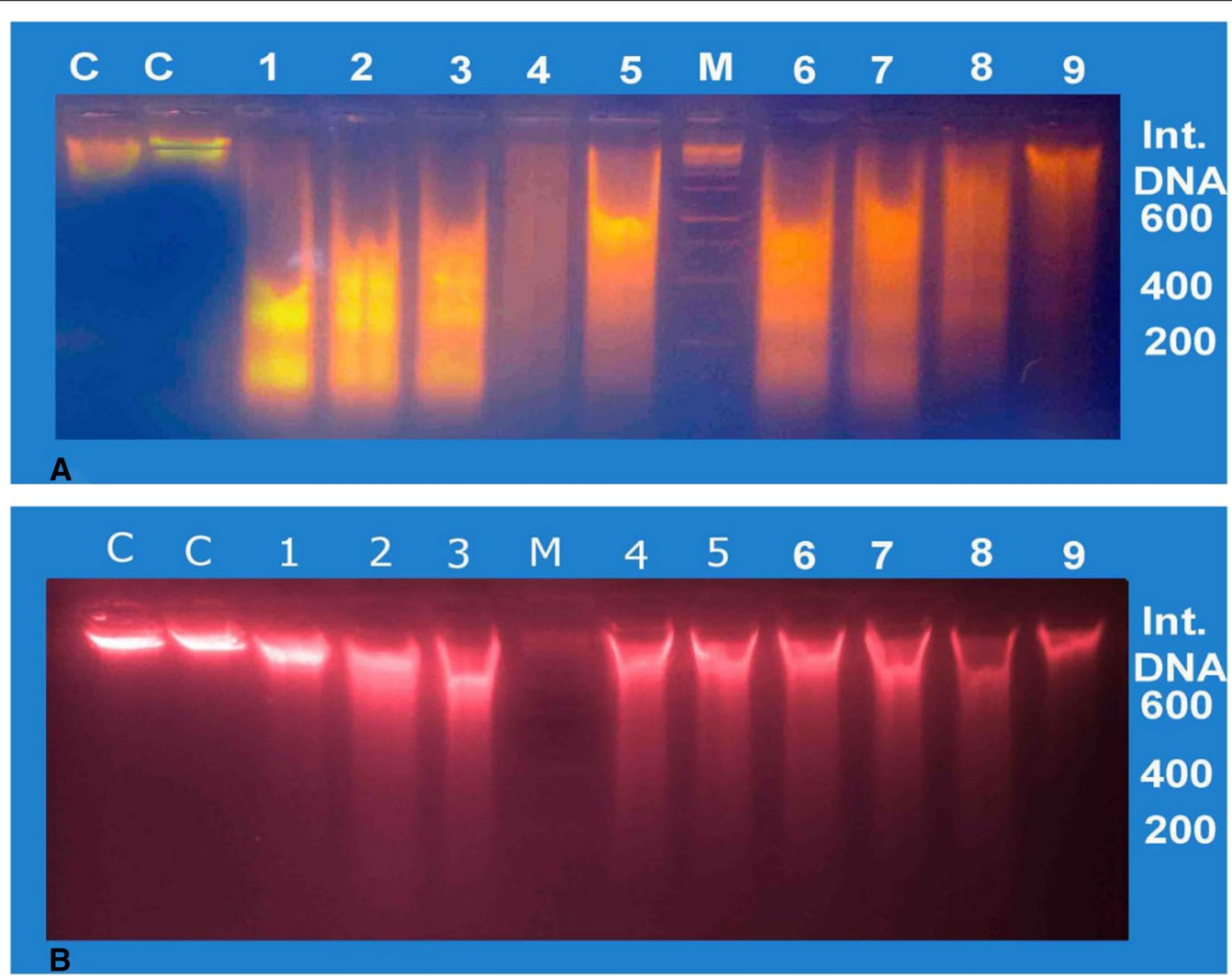

Fig. 7 Gel DNA electrophoresis of the liver (A) and kidneys (B) rats'specimens. Lanes C, Lanes 1-3, Lanes 4-6, Lanes 7-9: electrophoretic analyses of G1, G2, G3 \& G4; respectively. Lane M= marker (100 bp/DNA ladder). G1: control, G2: therapeutic design, G3: short-term prophylactic design, G4: long-term prophylactic design 
Table 3 The mean values of the optical density of necrotic smears of DNA at 200/400/\&600 bp locations and the intact DNA of the liver and kidneys cells of rats treated with Tamiflu compared to G1

\begin{tabular}{|c|c|c|c|c|}
\hline \multirow[t]{2}{*}{ Groups } & \multicolumn{4}{|l|}{ DNA Ladder in bp } \\
\hline & Intact DNA & $600 \mathrm{bp}$ & $400 \mathrm{bp}$ & $200 \mathrm{bp}$ \\
\hline \multicolumn{5}{|l|}{ G1 } \\
\hline Hepatic & $187.40 \pm 2.40$ & $76.40 \pm 5.18$ & $46.21 \pm 5.13$ & $27.15 \pm 2.92$ \\
\hline Renal & $192.70 \pm 5.24$ & $34.66 \pm 5.68$ & $25.83 \pm 7.93$ & $23.67 \pm 5.69$ \\
\hline \multicolumn{5}{|l|}{ G2 } \\
\hline Hepatic & $91.12 \pm 9.41^{* * *}$ & $138.90 \pm 7.14^{* * *}$ & $141.70 \pm 5.04 * * *$ & $138.70 \pm 3.89^{* * *}$ \\
\hline Renal & $122.30 \pm 7.014^{* * *}$ & $116.3 \pm 12.204^{* * *}$ & $54.67 \pm 11.80$ & $58.00 \pm 4.804^{* *}$ \\
\hline \multicolumn{5}{|l|}{ G3 } \\
\hline Hepatic & $71.92 \pm 11.50^{* * *}$ & $117.7 \pm 8.400^{* * *}$ & $102.20 \pm 3.62^{* * *}$ & $29.34 \pm 2.12$ \\
\hline Renal & $169.00 \pm 9.42$ & $43.73 \pm 5.60$ & $34.00 \pm 8.12$ & $22.33 \pm 7.89$ \\
\hline \multicolumn{5}{|l|}{ G4 } \\
\hline Hepatic & $143.6 \pm 2.54^{* *}$ & $154.80 \pm 3.36^{* * *}$ & $181.2 \pm 3.12^{* * *}$ & $162.90 \pm 4.10^{* * *}$ \\
\hline Renal & $57.41 \pm 8.984^{* * *}$ & $142.00 \pm 4.044^{* * *}$ & $124.10 \pm 7.764^{* * *}$ & $65.83 \pm 6.254^{* * *}$ \\
\hline
\end{tabular}

Values: means \pm SE. one-way ANOVA. G1: control, G2: therapeutic design, G3: short-term prophylactic design, G4: long-term prophylactic design. $P$ values: No asterisks $=$ non-significant $(P>0.05),{ }^{*}$ Significant $(P<0.05)$, ${ }^{* * H i g h l y ~ s i g n i f i c a n t ~}(P<0.01),{ }^{* * *}$ Very highly significant $(P<0.001)$ compared to their control, using oneway ANOVA

leads to liver injury". Kupffer cells, which are found in the normal liver, play an important role in both hepatic immunological homeostasis and the immunopathology of liver disorders. In response to acute/chronic inflammation, Kupffer cells generate high levels of proinflammatory cytokines and activation of these cells is a critical factor of peroxynitrite production and the severity of liver damage [34]. Moreover, the creation of neoantigens by medicines or their metabolites interacting with host proteins, such as albumin, could be the starting point for initiation of other immune cells, particularly cytotoxic $\mathrm{T}$ cells, resulting in liver injury. Hepatic toxicity caused by drugs might be dose/time-dependent or caused by a drug immune response mechanism [35]. In the present study, the liver injury attributable to Tamiflu shows that immuno-allergic factors, resulting from high dose or long duration of treatment, may have caused the liver damage. On the same manner, a previous study reported that OP had a hepatotoxic impact in rats given orally a therapeutic dose of one $\mathrm{mg} / \mathrm{kg}$.BW for various periods [10].

Also, as seen in G2 and G4, the nuclear alterations (pyknosis/karyorrhexis/karyolysis) in hepatocytes may be attributed to interference with DNA and protein synthesis in response to Tamiflu-toxic effects.

Hepatic fibrosis was shown in the branches of the hepatic portal veins and the central veins that exhibited markedly thickened endothelial walls. According to Amin et al. [36], fibrosis initiated by parenchymal cell destruction due to multiple injurious agents, and followed by inflammation, the latter activates resting hepatic stellate cells.
Tissue injury might result in a high plasma urea level. A high uric acid level is most commonly caused by inefficient uric acid elimination by the kidneys. Urate crystals can form when uric acid builds up, causing kidney injury [37]. So, the elevations in the levels of serum renal toxicity markers (such urea and uric acid) at G2 and G4 might be attributed to impairment/obstruction of protein and nucleic acid catabolism (an indication of the nephrotoxicity of Tamiflu), as it adversely affected the tubular and glomerular function of the rats [11]. On the other hand, creatinine is not reabsorbed; instead, it rises as a result of a lower glomerular filtration rate, which is used to detect renal impairment [37]. When the kidneys fail, the balance of fluid and electrolytes is disrupted, resulting in an imbalance of specific electrolytes. Hypokalemia can also affect the kidneys' ability to concentrate urine, leading to excessive urination and thirst (polyuria and polydipsia, respectively). Also, it can cause several alterations in kidney function, including impaired tubular transport and the development of chronic tubulointerstitial dysfunction [38]. The ability of the kidneys to maintain water homeostasis is known to be affected by chronic renal disease, and thus the risk of both hypo- and hypernatremia, with water changes resulting to cellular swelling or shrinking, can increase as the disease progresses [39]. In this study, the elevated serum creatinine concentration and electrolytes such as $\mathrm{Na}^{+}$, as well as the reduction in concentration of serum $\mathrm{K}^{+}$indicate tubular dysfunction [30]. Kang et al. [40] concluded that hypernatremia does occur when there is loss of body fluids containing less $\mathrm{Na}^{+}$than plasma. Nduka [41] reported that $\mathrm{Na}^{+}$increase is suspected to be due to the inability of the kidneys to excrete adequate 
$\mathrm{Na}^{+}$ion from the tubular fluid. These might explain the excess of $\mathrm{Na}^{+}$ion levels in the Tamiflu-administrated rats (G2\&4). Earlier researches [11, 42, 43] reported that renal impairment in the highest-dose group $(761 \mathrm{mg} / \mathrm{kg})$ of Tamiflu was accompanied by increased water intake, increased leukocyte count and increased bilirubin, urea, creatinine, and urine volume. Also, the same researchers found that the renal histological examination of their studies revealed degenerating/regenerating changes in the renal tubular epithelia, basement membranes and Bowman capsules; vacuolization in the renal tubular epithelia; and mineralization of tubules of renal medulla, as seen in our study. Glomerular dilation, degeneration of the epithelial cells lining the renal tubules, infiltration of inflammatory cells, hyperemia of medullary and cortical parts infiltrates were evident especially in G2 and G4 treated with Tamiflu. In previous studies in rats, experimental hyperuricemia, hyperuricemia and hypercreatininemia have also been associated with the development of mild renal disease, characterized by mild proteinuria, changes in renal blood vessels, glomerular damage, tubulointerstitial fibrosis, stimulation of inflammatory mediators and glomerulosclerosis [40, 44].

We know that OP is hydrolysed by hepatic carboxylesterases to oseltamivir carboxylate (its active metabolite), that excreted by the kidneys through glomerular filtration and renal tubular secretion [3]. Farrely [45] reported that repetitive doses/long-term use of Tamiflu caused the kidneys to become unable to hydrolyse the oseltamivir/Tamiflu sufficiently. So, its active metabolite forms excessive quantities of $\mathrm{ph}^{-}$will accumulate, leading to mineralization of the kidneys. This may explain the obtained results of this work. According to Basile et al. [46], the damage of the four major structures of the kidney (the tubules; the glomeruli; the interstitium; and the intrarenal blood vessels) is the major reason resulted in acute kidney injury.

In addition, the biochemical and histopathological alterations observed in the present study were in parallel with the molecular findings. The production of reactive oxygen species (ROS) by Tamiflu toxic metabolism or the consequent mitochondrial damage might cause direct or indirect oxidative DNA damage. Our results of hepatic DNA electrophoresis demonstrated that the oral administration of Tamiflu significantly induced necrosis, especially in G2 and G4 (therapeutic and long-term prophylactic doses) at three bp location (600, 400 and $200 \mathrm{bp}$ ), which increased gradually depending on the doses accumulation (dose-dependent) as well as long duration (time-dependent). While the integrity of hepatic DNA in G3 (short-term prophylactic dose) gave necrotic hepatic DNA smears at two bp location (600, and $400 \mathrm{bp}$ ) only. In addition, renal DNA integrity in
G2 and G4 (the therapeutic and long-term prophylactic doses) gave necrotic DNA smears at two bp location (200 and 600) and three bp location (600, 400 and $200 \mathrm{bp}$ ), respectively. On the other hand, renal DNA integrity of G3 at 200, 400 and 600 bp location did not show any significant change compared to the control group. Thus, the effect of the examined drug on the integrity of DNA in the liver samples was higher than in the kidney's samples. The optical density gradually increased depending on the doses accumulation as well as long duration. El-Ganzuri et al. [12] and Abdel-Ghaffar [13] reported that the therapeutic dose, short-term and long-term prophylactic doses gave necrotic DNA smears, but the intensity of such dose was both timeand dose-dependent.

Finally, the reasons that lead to hepatoxicity and nephrotoxicity due to Tamiflu administration should be adequately focused and addressed. In general, increased vigilance during pre-clinical drug/vaccines development and clinical trials, serum hepatic/renal enzymes monitoring with particular medications and the potential finding of both diagnostic/prognostic biomarkers are all ways to prevent drug hepato- or/and renal toxicities.

\section{Conclusions}

It was found that Tamiflu/OP at its therapeutic and long-term prophylactic doses caused structural and functional hepato- and nephrotoxicity; hence, it should be consumed with caution and not used for long periods (time-dependent) or/and repetitive doses (accumulative-dose-dependent) especially with patients suffer from liver or/and kidney dysfunction, while the shortterm prophylactic dose of Tamiflu appear to be relatively safe and could be explored for oral medications.

\section{Abbreviations}

ALT: Alanine aminotransferase; AST: Aspartate aminotransferase; ALP: Alkaline phosphatase; GGT ( $\gamma$-GT): Gamma-glutamyltransferase; Total Bili: Total bilirubin; Direct Bili.: Direct bilirubin.

\section{Acknowledgements}

Not applicable.

\section{Authors' contributions}

WHA conceived and designed the experiments; WHA and EAA performed the experiments; analysed and interpreted the data; contributed materials, analysis data; wrote the paper. Both authors read and approved the final manuscript.

\section{Funding}

The Sector of Higher Studies, Ain Shams University, funded the paper with 10000 Egyptian pound to complete some analyses, in addition to the chemicals and glassware. Also, the animal accommodation at the animal house, Zoology Department, Faculty of Science, Ain Shams University, was free of charge for the Faculty Members. 


\section{Availability of data and materials}

The datasets supporting the conclusions of this article are included within the article.

\section{Declarations}

\section{Ethics approval and consent to participate}

This study follows guidelines for the care and use of experimental animals established by the Committee for the purpose of control and supervision of experiments on animals. Animal procedures were also made in accordance with the Faculty of Science protocol, Ain Shams University (NO: ASU/7/05).

\section{Consent for publication}

Not applicable.

\section{Competing interests}

The authors declare no conflict of interest.

\section{Author details}

1 Department of Zoology, Faculty of Science, Ain Shams University, Cairo, Egypt. ${ }^{2}$ Biology Department, Faculty of Science, Taibah University, Yanbu Branch, Saudi Arabia.

Received: 9 October 2021 Accepted: 21 December 2021

Published online: 25 January 2022

\section{References}

1. Mendel DB, Tai CY, Escarpe PA, Li W, Sidwell RW, Huffman JH, Sweet C, Jakeman KJ, Merson J (1998) Oral administration of a prodrug of the influenza virus neuraminidase inhibitor GS 4071 protects mice and ferrets against influenza infection. Antimicrob Agents Chemother 42:640-646

2. Choy KT, Wong AY, Kaewpreedee P, Sia SF, Chen D, Hui KPY, Chu DKW, Chan MCW, Cheung PP, Huang X (2020) Remdesivir, lopinavir, emetine, and homoharringtonine inhibit SARS-CoV-2 replication in vitro. Antiviral Res 178:104786

3. Jefferson T, Jones MA, Doshi P, Del-Mar CB, Heneghan CJ, Hama R, Thompson MJ (2012) Neuraminidase inhibitors for preventing and treating influenza in healthy adults (Review). Cochrane Database Syst Rev 1:CD008965

4. Hsu J, Santesso N, Mustafa R, Brozek J, Chen YL, Hopkins JP, Cheung A, Hovhannisyan G, Ivanova L, Flottorp SA, Saeterdal I, Wong AD, Tian J, Uyeki TM, AkI EA, Alonso-Coello P, Smaill F, Schunemann HJ (2012) Antivirals for treatment of influenza: a systematic review and meta-analysis of observational studies. Ann Intern Med 156(7):512-524

5. Wang K, Shun-Shin M, Gill P, Perera R, Harnden A, Shun-Shin G, Harnden P (2012) Neuraminidase inhibitors for preventing and treating influenza in children (published trials only) (Review). Cochrane Database Syst 4:CD002744

6. Muthuri SG, Myles PR, Venkatesan S, Leonardi-Bee J, Nguyen-Van-Tam $J$ (2013) Impact of neuraminidase inhibitor treatment on outcomes of public health importance during the 2009-2010 influenza A (H1N1) pandemic: A systematic review and meta-analysis in hospitalized patients. J Infect Dis 207:553-563

7. Kamps BS, Hoffmann C, Preiser W (2006) Influenza Report 2006. Flying Publisher, Paris, Cagliari, Wuppertal, Sevilla

8. Hayden FG, Treanor JJ, Fritz RS, Lobo M, Betts RF, Miller M, Straus SE (1999) Use of the oral neuraminidase inhibitor oseltamivir in experimental human influenza: randomized controlled trials for prevention and treatment. JAMA 282(13):1240-1246

9. Davies BE (2010) Pharmacokinetics of oseltamivir: an oral antiviral for the treatment and prophylaxis of influenza in diverse populations. J Antimicrob Chemother 65(2):ii5-ii10

10. Al-Rikabi FM (2012) Evaluation of selected parameters of rat liver injury following repeated administration of oseltamivir for different periods. Iraq J Vet Med 36(1):137-144

11. Al-Rikabi FM (2014) The Nephrotoxic Impact of Oseltamivir in Male Albino Rats after Repeated Exposure. Pharmacology \& Pharmacy 5:479-486
12. El-Ganzuri M Hassab El-Nabi S, Saafan N, Abdel-Ghaffar WH (2016) Molecular studies of the effects of the antiviral drug, oseltamivir (Tamiflu), on the DNA of the testes' cells and the leucocytes of the male adult albino rats. Egypt J Zool 65:159-184

13. Abdel-Ghaffar WH (2017) The effects of oseltamivir (Tamiflu) on the male adult albino rats: Histological, ultrastructural, biochemical, and molecular studies. Ph. D. Thesis, Faculty of Science, Ain Shams University.

14. Mohamed AF (2018) Effect of Oseltamivir phosphate (Tamiflu H) on the pre- and postnatal development of the albino rats' cerebellar cortex (Histological and Morphometric studies). Al-Azhar Med J 47:781-809

15. Ciociola AA, Cohen LB, Kulkarni P (2014) The FDA-Related Matters Committee of the American College of Gastroenterology": How drugs are developed and approved by the FDA: current process and future directions. Am J Gastroenterol 109:620-623

16. FDA (1991). Food and Drug Administration. 21 code of Federal Regulations, 314. $126(b)(2)$.

17. Lee N, Chan PK, Hui DS, Choi KW (2009) Viral loads and duration of viral shedding in adult patients hospitalized with influenza. J Infect Dis 200:492-500

18. Hayden FG, Belshe R, Villanueva C, Lanno R, Hughes C, Small I, Dutkowski R, Ward P, Carr J (2004) Management of influenza in households: a prospective, randomized comparison of oseltamivir treatment with or without postexposure prophylaxis. J Infect Dis 189:440-449

19. Peters PH Jr, Gravenstein S, Norwood P, De Bock V, Van Couter A, Gibbens M, von Planta TA, Ward P (2001) Long-term use of oseltamivir for the prophylaxis of influenza in a vaccinated frail older population. J Am Geriatr Soc 49:1025-1031

20. Paget GE, Barnes JM (1964) Toxicity tests. In: Lawrence DR, Bacharach AL (eds) Evaluation of drug activities: pharmacometrics, vol 1. Academic Press, London, p 161

21. Aljanabi SM, Martinez I (1997) Universal and rapid salt extraction of high quality genomic DNA for PCR-based techniques. Nucl Acids Res 25:4692-4693

22. Hassab El-Nabi SE (2004) Molecular and cytogenetic studies on the antimutagenic potential of eugenol in human lymphocytes culture treatment with depakin and apetryl drugs. J Egypt Ger Soc Zool 34(C):171-196

23. NCIRD (2001). Centers for Disease Control and Prevention, Nationa Center for Immunization and Respiratory Diseases (NCIRD). https://www. cdc.gov/flu/professionals/antivirals/summary-clinicians.htm.

24. El-Sayed WM, Al-Kahtani MA (2011) Potential adverse effects of oseltamivir in rats: males are more vulnerable than females. Can J Physiol Pharmacol 89:623-630

25. Akanji MA, Nafiu MO, Yakubu MT (2008) Enzyme activities and histopathology of selected tissues in rats treated with potassium bromate. Afr J Biomed Res 11:87-95

26. Thapa BR, Walia A (2007) Liver function tests and their interpretation. Indian J Pediatr 74:663-671

27. Abd El-Ghffar EA, Shehata SM (2018) Antioxidant and anti-inflammatory effects of Acrocarpus fraxinifolius on hyperglycemia, hyperlipidemia, and liver/kidney dysfunctions against alloxan induced Type 1 diabetes in rats. IJTK 17:223-232

28. Daniel SP, Marshal MK (1999) Evaluation of the liver: Laboratory tests, Schiff's diseases of the liver 8thedUSA JB Lippincott publication, 20-239.

29. Abd El-Ghffar EA, Abdel-Aal A (2018) Ameliorating effect of L-Cysteine on lead acetate-induced hepatotoxicity and nephrotoxicity in male mice. Prog Nutr 20:79-89

30. Yakubu MT, Adeshina AO, Ibrahim OO (2012) Toxicological evaluation of aqueous leaf extract of Senna alata in pregnant Wistar rats. International Journal of Current Research and Reviews 4(8):89-109

31. Santucci P, Bouzid F, Smichi N, Poncin I, Kremer L, De Chastellier C, Drancourt M, Canaan S (2016) Experimental models of foamy macrophages and approaches for dissecting the mechanisms of lipid accumulation and consumption during dormancy and reactivation of tuberculosis. Front Cell Infect Microbiol 6:122

32. Michael PH, Cynthia J (2006) Mechanisms of drug-induced liver injury. AAPS J 8(1):E48-E54

33. Farrag OS, Salman D, Ali F, Sayed AS, Mahmoud ME, Abd-El Raheem AA (2020) Impact of continuous treatment with propylthiouracil on renal and hepatic functions in rabbits. J Appl Vet Sci 5(2):49-60 
34. Abd El-Ghffar EA, Eldahshan OA, Barakat A, Efferth T (2018) Prophylactic effect of Eugenia Aquea extract against oxidative stress and inflammation associated with development of arthritis in AIA rats model. Food Funct 9:6643-6651

35. Mastroianni A, Vangeli V, Greco S, Urso F, Greco F, Chidichimo L, Mauro MV (2021) Oseltamivir and acute hepatitis, reality association or coincidence? Antiviral Ther. https://doi.org/10.1177/13596535211041494

36. Amin AM, Kazem AH, Hassan SM, Youssef EA, Khalil EM (2010) Effect of silymarin on liver injury induced by carbon tetrachloride in rats: histopathological and immunohistochemical studies. Egypt J Exp Biol (Zool) 6(1):107-115

37. Boyd RI (1949) Hepatic function during the hypoproteinemia of the renal disease. Arch Intern Med (Chic) 83(3):298-304

38. Mujais SK, Katz AL (2000) Potassium deficiency. In: The Kidney: Physiology and Pathophysiology, Seldin DW, Giebisch G (Eds), Lippincott Williams \& Wilkins, p.1615.

39. Kovesdy CP (2012) Significance of hypo- and hypernatremia in chronic kidney disease. Nephrol Dial Transplant 27:891-898

40. Kang S, Kim W, Oh MS (2002) Pathogenesis and treatment of hypernatremia. Nephron 92(1):14-17

41. Nduka N (1999) Water and electrolytes. In: Nduka N (ed) Clinical biochemistry for students of Pathology. Longman Nigeria Plc., Abuja, p 28

42. El-Tantawi HG (2007) Histological and histochemical changes of liver, kidney and testis of albino rat after experimental application of oseltamivir phosphate (Tamiflu). J Arab Soc Med Res (JASMR) 2(1):35-43

43. Hama R (2015) The mechanisms of adverse reactions to oseltamivir: part II. Delayed type reactions. Clin Microbiol 4:224

44. Sanchez-Lozada LG, Tapia E, Avila-Casado C, Soto V, Franco M, Santamaría J, Nakagawa T, Rodríguez-Iturbe B, Johnson RJ, Herrera-Acosta J (2002) Mild hyperuricemia induces glomerular hypertension in normal rats. Am J Physiol Renal Physiol 283:F1105-F1110

45. Farrely J (2001) Pharmacologists' Review. Application Number 21-246, Center for Drug Evaluation and Research, 1-18

46. Basile DP, Anderson MD, Sutton TA (2012) Pathophysiology of acute kidney injury. Compr Physiol 2(2):1303-1353

\section{Publisher's Note}

Springer Nature remains neutral with regard to jurisdictional claims in published maps and institutional affiliations.

\section{Submit your manuscript to a SpringerOpen ${ }^{\circ}$ journal and benefit from:}

- Convenient online submission

- Rigorous peer review

- Open access: articles freely available online

- High visibility within the field

- Retaining the copyright to your article 